\title{
ROLE OF COLOR DOPPLER U/S AND MRI FOR DIAGNOSIS OF PLACENTA ACCRETA
}

\author{
By \\ Ahmed M. Siddik, Mostafa H. Hegab and Abd El-Rahman M. Anbar \\ Department of Obstetrics and Gynecology, Faculty of Medicine, AL-Azhar University \\ E-mail: ahmedsiddik82@gmail.com
}

\begin{abstract}
Background: The worldwide incidence of placenta accreta (PA) is rapidly rising, following the trend of increasing cesarean delivery. Antenatal diagnosis is highly desirable because outcomes are optimized when delivery occurs at a level III or IV maternal care facility before the onset of labor and with avoidance of placental disruption. The primary diagnostic modality for antenatal diagnosis is obstetric color Doppler ultrasonography (CDUS). Magnetic Resonance Imaging (MRI), although widely employed, has yet to clearly demonstrate a significant improvement in management, but it is expensive and requires expertise that is rarely available in most low-income countries and many medium income countries.
\end{abstract}

Objective: To evaluate and compare the accuracy of CDUS and MRI in the diagnosis of PA and to define the most relevant specific features that may predict placental invasion.

Patients and methods: A case control study was conducted at AL- Azhar University Hospitals during the interval between November 2017 and November 2020, total set of 50 patients in the third trimester of pregnancy with diagnosis of placenta accreta and at least one previous caesarean section (CS). Patients were equally divided into 2 groups; Group I: Control group diagnosed as PA by CDUS. Group II: Study group diagnosed as placenta accreta by CDUS and subjected to MRI. With inclusion and exclusion criteria, all included women was subjected to; history taking, physical examination, obstetric CDUS and MRI scan was added for Group II only to pick up features suggestive of PA.

Results: The sensitivity and specificity of CDUS were $100 \%$ and $72 \%$, whereas the sensitivity and specificity of MRI were $76 \%$ and $52 \%$, respectively, in their ability to diagnose PA. The highest sensitivity of individual CDUS and MRI markers in predicting PA were obliteration of the retroplacental clear space (63.6\%) and focal interruption in the myometrial wall (73.7\%), respectively.

Conclusion: Ultrasound imaging is the mainstay of screening for placenta accreta. MRI appears to be complementary to ultrasonography, especially when there are few ultrasound signs or if there is a suspicion for invasion into surrounding organs.

Keywords: Placenta accreta, Color Doppler Ultrasonography, MRI.

\section{INTRODUCTION}

It has been suggested that cesarean scar pregnancy represents a precursor of one of the different grades of PA disorders (Timor-Tritsch et al., 2014).

Maternal mortality and morbidity are reduced when women with PA disorders, deliver in a center of excellence by a multidisciplinary care team with experience in managing the surgical risks and perioperative challenges presented by these disorders (Silver et al., 2015).

Irrespective of the imaging modality used, prenatal diagnosis of PAS disorders remains subjective, with accuracy depending on the experience of the operator, which has so far been limited by the rarity of the condition and the lack of 
training programs similar to those existing for the screening of fetal aneuploidies and fetal anatomical defects, such as congenital heart defects (Jauniaux et al., 2018).

The primary diagnostic modality for antenatal diagnosis is obstetric ultrasonography. Features of accreta visible by ultrasonography may be present as early as the first trimester; however, most women are diagnosed in the second and third trimesters (Eller et al., 2011).

Different ultrasound imaging techniques have been used over the last 30 years to diagnosis PA disorders in the third trimesters of pregnancy, including grey-scale and color Doppler sonography (Jauniaux et al., 2016).

The combination of grey-scale and color Doppler imaging ultrasound markers is reported to have increased the sensitivity of ultrasound imaging to around $90 \%$ with negative predictive values ranging between $95 \%$ and $98 \%$ (D'Antonio et al., 2013).

The main MRI features of placenta accreta include abnormal uterine bulging, dark intraplacental bands on T2-weighted imaging, heterogeneous signal intensity within the placenta, disorganized placental vasculature (Meng et al., 2013).

The present work aimed to evaluate and compare the accuracy of CDUS and magnetic MRI in the diagnosis of placenta accreta and to define the most relevant specific features that may predict placental invasion.

\section{PATIENTS AND METHODS}

A prospective case control study was conducted at AL- Azhar University
Hospitals during the interval between November 2017 and November 2020. This study was approved by the Ethics Committee for Human Research at Faculty of Medicine, AL- Azhar University. Informed verbal consent was obtained from every participant. All the pregnant participants were in the third trimester of pregnancy.

Total set of 50 patients were recruited from inpatients with diagnosis of PA by CDUS and at least one previous caesarean section delivery. They were equally classified into 2 groups:

Group I (G I): Control group was formed of patients diagnosed as PA by CDUS.

Group II (G II): Study group diagnosed as PA by CDUS and MRI.

\section{Inclusion criteria:}

- Pregnant women with PA, with implantation on the lower uterine segment.

- Previous uterine surgery (e.g., cesarean section, myomectomy).

\section{Exclusion criteria:}

- Presence of medical disorders (diabetes, hypertension, epilepsy, etc.).

- Presence of metallic prosthesis (prosthetic valves, pacemakers, cochlear implants, or plates and screws).

Obstetric ultrasonography was first used to screen the placental tissue in a systematic fashion. In the presence of placental sonolucent lakes, examination was completed using superimposed color Doppler flow.

MRI scan was added only for GII to pick up features suggestive of PA. MRI 
scans were performed on a Siemens Magnetom Avanto 1.5-T scanner. T2weighted single-shot fast spin echo sequences acquired in the axial, sagittal, and coronal planes using the following parameters (TR 5000/TE $110 \mathrm{~ms}$, echo train length 13-15, slice thickness 5-7 mm, gap 1-2 mm, Field of view $24-38 \mathrm{~cm}$, excitations (NSA) 3 and matrix $304 \mathrm{x}$ 512).

Statistical analysis: Preceded data were entered into the statistical package for the social sciences software program, version 21 to be statistically analyzed (SPSS Inc., Chicago, Illinois, USA).

Data were summarized using means and SD for quantitative variables and using frequencies and percentages for qualitative ones. Comparison between groups was performed using KruskalWallis and Mann-Whitney $U$ tests for quantitative variables and the $\mathrm{x} 2$ - test for qualitative ones. $\mathrm{P}$ values less than 0.05 were considered statistically significant.

\section{RESULTS}

The demographic characteristics of the participants of G I showed; mean values were $29.3,4.2,3.4,2.3,1$ for age, parity, cesarean deliveries, abortion, dilation and curettage respectively.

The demographic characteristics of the Group II showed; $p$ values were significant for number of cesarean deliveries, number of abortions and number of years from last CS. As regard age \& parity the 2 groups are demographically similar (Table 1).

Table (1): The Demographic Characteristics of G I and G II

\begin{tabular}{|c|c|c|c|c|c|c|c|}
\hline Groups & \multicolumn{3}{|c|}{ G I } & \multicolumn{4}{c|}{ G II } \\
Parameters & \multicolumn{3}{|c|}{ N=25 } & \multicolumn{3}{c|}{ N=25 } \\
\hline Criteria & Mean & SD & Range & Mean & SD & Range & P \\
\hline Age & 29.33 & \pm 4.89 & $20-38 y$ & 30.13 & \pm 5.24 & $20-39 y$ & 0.05 \\
\hline Parity & 4.26 & \pm 1.25 & $2-7$ & 3.72 & \pm 1.69 & $1-7$ & 0.06 \\
\hline Cesarean deliveries & 3.44 & \pm 0.82 & $2-5$ & 3.05 & \pm 1.23 & $1-6$ & 0.04 \\
\hline Abortions & 2.37 & \pm 1.01 & $1-4$ & 1.63 & \pm 1.10 & $0-4$ & 0.01 \\
\hline Dilation and curettage & 1.00 & \pm 0.67 & $0-2$ & 2 & \pm 0.75 & $0-3$ & 0.02 \\
\hline Myomectomies & 1.02 & \pm 0.59 & $0-2$ & 2.09 & \pm 0.93 & $1-4 y$ & 0.01 \\
\hline Last CS delivery & 2.69 & \pm 1.04 & $1-5 y$ & 2.20 & \pm 1.39 & $0-6 y$ & 0.04 \\
\hline
\end{tabular}

Clinical history of previous uterine surgery was $93.1 \%$ of patients had cesarean section deliveries, $8.6 \%$ of them had myomectomy and $50 \%$ of them had dilation and curettage.

Placenta was anteriorly situated in $74.1 \%$ of patients and posteriorly situated in $25.9 \%$ of them. In the demographic characteristics of the studied cases $\mathrm{P}$ values were significant for number of CS, number of abortions, number of years from last abortion and number of years from last CS. As regard age and parity, the 2 groups were demographically similar.

Multiple findings were more common than a single isolated finding. On CDUS, obliteration of the retroplacental clear space was found in $63.6 \%$ of cases, the 
interruption of the posterior bladder walluterine interface in $54.5 \%$ of cases, decreased myometrial thickness in $54.5 \%$ of cases, presence of placental vascular spaces in $18.2 \%$ of cases, and presence of hypervascularity of the interface between the uterine serosa and the bladder wall in $45.4 \%$ of cases (Table 2 ).

Table (2): Sensitivity, specificity, positive predictive value, and negative redictive value of ultrasonography diagnostic criteria for placenta accreta in both groups

\begin{tabular}{|c|c|c|c|c|c|}
\hline Items & Sensitivity & Specificity & PPV & NPV & Accuracy \\
\hline Loss of RCS & 63.64 & 66.44 & 98.66 & 75.00 & 82.61 \\
\hline Loss of BUI & 54.55 & 86.34 & 89.55 & 70.59 & 78.26 \\
\hline VL & 18.18 & 97.12 & 94.56 & 57.14 & 60.87 \\
\hline Increased vascularity & 45.45 & 91.67 & 83.33 & 64.71 & 69.57 \\
\hline Decreased MT & 54.55 & 87.88 & 77.56 & 70.59 & 78.26 \\
\hline
\end{tabular}

NPV, negative predictive value; PPV, positive predictive value; MT, myometrial thickness; RCS, retroplacental clear space; BUI, bladder uterine interface; VL, vascular lacunae.

In G II, the MRI features of patients showed that they had accreta: heterogeneous placental signal intensity was found in $63.64 \%$, dark intraplacental bands in $45.5 \%$, focal interruption in the myometrial wall in $72.73 \%$ of cases, uterine bulging in $27.3 \%$ of cases, and direct visualization of invasion of pelvic structures in $9 \%$ of case. Focal interruption in the myometrial wall was found to have the highest sensitivity $(73.7 \%)$ followed by heterogeneous signal intensity within the placenta $(63.6 \%)$ and then dark intraplacental bands $(45.5 \%)$ (Tables 3).

Table (3): Sensitivity, specificity, positive predictive value, and negative predictive value of MRI diagnostic criteria for placenta accreta in both groups

\begin{tabular}{|l|l|l|l|l|l|}
\hline Items & Sensitivity & Specificity & PPV & NPV & Accuracy \\
\hline Interruption in myometrial wall & 73.73 & 89.44 & 85.88 & 80.30 & 86.96 \\
\hline Heterogeneous intensity & 63.64 & 95.12 & 91.33 & 75.23 & 82.61 \\
\hline Dark intraplacental bands onT2 & 45.45 & 88.87 & 55.88 & 66.67 & 73.91 \\
\hline Uterine bulging & 27.27 & 98.12 & 79.88 & 60.33 & 65.22 \\
\hline Invasion of pelvic structures & 79.09 & 95.66 & 93.66 & 54.55 & 56.52 \\
\hline
\end{tabular}

NPV, negative predictive value; PPV, positive predictive value

According to the operative findings and/or pathology, CDUS was found to provide true-positive results in $100 \%$ of patients proved to be accreta cases. MRI provided true-negative results in $52 \%$ of patients (Table 4).

Table (4): Sensitivity, specificity, positive predictive value, and negative predictive value of ultrasound and MRI in this study

\begin{tabular}{|c|c|c|c|c|c|}
\hline Items & Sensitivity & Specificity & PPV & NPV & Accuracy \\
\hline Final CDUS & 100 & 72 & 89.55 & 86.96 & 72.73 \\
\hline Final MRI & 76 & 52 & 87.5 & 73.33 & 78.26 \\
\hline
\end{tabular}

NPV, negative predictive value; PPV, positive predictive value; US, ultrasonography. 


\section{DISCUSSION}

The present study was a prospective study included 50 pregnant women at 28 weeks of gestation or more, to determine the need for MRI in the radiological diagnosis of candidate cases for placenta accreta. Sensitivity and specificity of CDUS were $100 \%$ and $40 \%$, whereas for MRI sensitivity and specificity were 76 and $52 \%$, respectively, in their ability to diagnosis placenta accreta. This is in disagreement with a study performed in 2010, which stated that US had a sensitivity of $93 \%$ and specificity of $71 \%$ compared with MRI, which had a sensitivity of $80 \%$ and specificity of $65 \%$ (Dwyer et al., 2010).

Another comparable study confirmed that obstetric color Doppler ultrasonography is highly reliable to diagnose or exclude the presence of PA, and found MRI to be an excellent tool for the staging and topographic evaluation of PA. They stated that MRI and Doppler US show no statistical difference in identifying patients with PA, whereas MRI was statistically better than CDUS in characterizing the topography of invasion. MRI showed accuracy of $100 \%$ in assessing the depth of placental infiltration versus $75 \%$ by CDUS (Masselli et al., 2010).

A recent study by McLean et al. in cluding a large cohort of gravid patients at risk for placenta accreta failed to demonstrate the incremental use of MRI for placenta accreta changes delivery mode in a stratified analysis. Such a study had performed MRI in a small proportion of the cohort that was only $28.7 \%$, also being a retrospective study handles a percentage of CDUS bias regarding analytical data (McLean et al., 2011).

Warshak et al. compared CDUS and postcontrast MRI performance in the diagnosis and evaluation of placenta accreta (Warshak et al., 2016). They reported on 39 cases of confirmed placenta accreta with an unpaired study design. Ultrasound had a sensitivity of $77 \%$ and specificity of $96 \%$, and MRI with gadolinium enhancement had a sensitivity of $88 \%$ and specificity of $100 \%$. The high statistical values in the aforementioned study may be because they had performed routine transvaginal ultrasound in addition to the transabdominal approach in evaluating their studied cases as well as gadolinium enhancement in their MRI examination, as according to them it had more clearly delineated the outer placental surface relative to the myometrium (Lax et al., 2017).

Our study agrees with the findings of Lax et al (2017). We also found that the focal interruption in the myometrium was seen in $72.7 \%$, abnormal heterogeneous signal intensity of the placenta was seen is $63.6 \%$, dark intraplacental bands on $\mathrm{T} 2$ sequences was seen in $45.5 \%$ of the surgically/pathologically proved cases of placenta accreta, and were absent in most normal placenta.

Moreover, our data suggest that the lack of loss/irregularity of clear space may help exclude the diagnosis of placenta accreta. If the echolucent area between the placenta and the uterus is preserved, especially in cases of low anterior placenta, placenta accreta is unlikely to occur. We, therefore, confirm the findings of Comstock and Finberg and Williams 
AHMED M. SIDDIK et al.,

that the clear space should not be used as a single diagnostic criterion, but should be combined with other criteria with greater PPV (Comstock, 2011).

We looked for intraplacental lacunae using CDUS. Our investigative hypothesis was to determine a relationship between intralacunar turbulent flow and grade of placenta accreta. All cases with placenta percreta had more than six lacunae with turbulent flow inside. In our series, placenta lacunae had a relatively high PPV and low NPV of 100 and 57.14\%, respectively, whereas a strong relationship between multiple placental lacunae with irregular shape and placenta accreta has been suspected by other authors (Finberg and Williams, 2011).

In this study, we relied upon spin echo sequences in assessing placental invasion to the myometrium or beyond as follows:

- T2-weighted images helped in distinguishing the intermediate signal intensity placental bulk from the inner and outer myometrial dark layers as well as from the myometrium itself, which is of more intermediate signal intensity

- T1-weighted images showed distended tortuous placental/myometrial vessels as clustered bright signal intensities (probably due to blood stagnation, especially in the pelvic and lower limb vessels accompanying pregnancy). The interface between the urinary bladder and the myometrium was also more clarified at that sequence. T2-weighted images may display overestimation of percreta. In such cases, we had to check for disruption of the fat plane overlying the uterine serosa in T1-weighted sequence.

\section{CONCLUSION}

Ultrasound imaging is the mainstay of screening for placenta accreta. MRI appears to be complementary to CDUS, especially when there are few ultrasound signs or if there is a suspicion for invasion into surrounding organs. Sensitivity in the diagnosis of placenta accreta was $100 \%$ with CDUS and $76 \%$ for MRI. Specificity was $72 \%$ with ultrasonography and $52 \%$ for MRI respectively. Obliteration of the retroplacental clear space was found to have the highest sensitivity $(63.6 \%)$ as a sign of CDUS. Focal interruption in the myometrial wall was found to have the highest sensitivity $(73.7 \%)$ as a sign of MRI.

\section{REFERENCES}

1. Comstock CH (2011): The antenatal diagnosis of placenta accreta. Curr Opin Obstet Gynecol., 23:117-122.

2. D'Antonio F, Iacovella $\mathrm{C}$ and Bhide $\mathrm{A}$ (2013): Prenatal identification of placenta accreta using ultrasound: systematic review. Ultrasound Obstet Gynecol., 42:509 -617.

3. Dwyer BK, Belogolovkin V, Tran L, Rao A, Carroll I and Barth R (2010): Prenatal diagnosis of placenta accreta: sonography or magnetic resonance imaging? Ultrasound Med., 27:1275-1281.

4. Eller AG, Bennett MA and Sharshiner M (2011): Maternal morbidity in cases of placenta accreta managed by a multidisciplinary care team compared with standard obstetric care. Obstet Gynecol., 117:331-337.

5. Finberg HJ and Williams JW (2011): Placenta accreta: prospective sonographic diagnosis in patients with placenta previa and prior cesarean section. J Ultrasound Med., 11:333-343. 
6. Jauniaux E, Bhide $A$ and Wright JD (2016): Placenta accreta. In: Normal and Problem Pregnancies. 7th Ed. Philadelphia: Elsevier., 120: 456-466.

7. Jauniaux E, Chantraine F, Silver RM and Langhoff-Roos J (2018): FIGO consensus guidelines on placenta accreta spectrum disorders: Epidemiology. Int Jornal Gynecol Obstet., 54: 212:220.

8. Lax A, Prince MR, Mennitt KW, Schwebach JR and Budorick NE (2017): The value of specific MRI features in the evaluation of suspected placental invasion. Magn Reson Imaging., 25:87-93.

9. Masselli G, Brunelli R, Casciani E, Polettini E, Piccioni MG and Anceschi M (2010): Magnetic resonance imaging in the evaluation of placental adhesive disorders: correlation with color Doppler ultrasound. Eur Radiol., 18:1292-1299.

10. McLean LA, Heilbrun ME, Eller AG, Kennedy AM and Woodward PJ (2011): Assessing the role of magnetic resonance imaging in the management of gravid patients at risk for placenta accreta. Acad Radiol., 18:1175- 1180 .

11. Meng $X$, Xie $L$ and Song $W$ (2013): Comparing the diagnostic value of ultrasound and magnetic resonance imaging for placenta accreta: a systematic review and metaanalysis. Ultrasound Med Biol., 39: 1958-1965.

12. Silver RM, Fox KA and Barton JR (2015): Center of excellence for placenta accreta. Am Jornal Obstet Gynecol., 212:561-568.

13. Timor-Tritsch IE, Monteagudo A and Cali G (2014): Cesarean scar pregnancy is a precursor of PAS. Ultrasound Obstet Gynecol., 44:346-353.

14. Warshak CR, Eskander R, Hull AD, Scioscia AL, Mattrey RF and Benirschke K, (2016): Accuracy of ultrasonography and magnetic resonance imaging in the diagnosis of placenta accreta. Obstet Gynecol., 108:573-581. 
دور الأشعة التليفزيونية و الدوبلر الملون و أشعة الرنين المغناطيسى فى تشخيص المشيمة المئه الملتصقة أحمد محمد صديق، مصطفى حسين حجاب، عبد الرحمن مصطفى عنبر قسم التوليد وأمراض النساء، كلية الطب، جامعة الأزهر

E-mail: ahmedsiddik82@gmail.com

خلفيــة البحــث: يمكـن أن تحــدث المشــيمة الملتصــقة وفيــات الأمهــات بسـبـب نزيــف حــاد

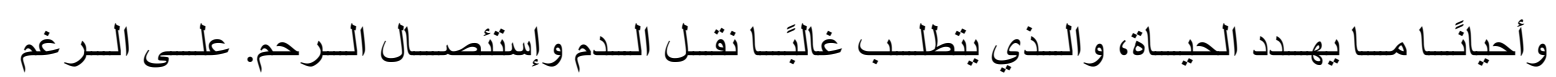

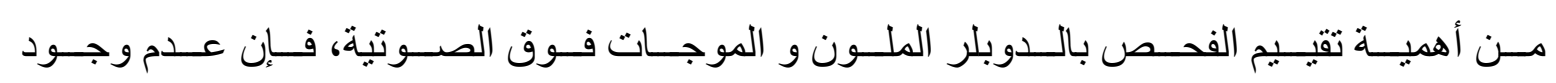

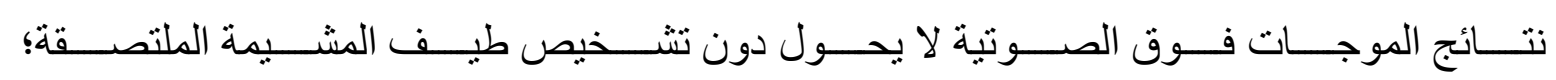

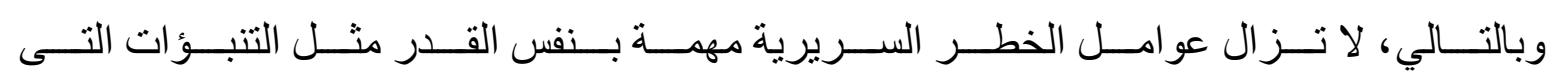

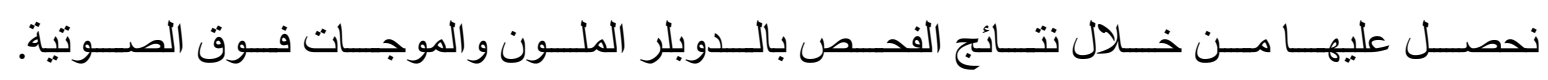

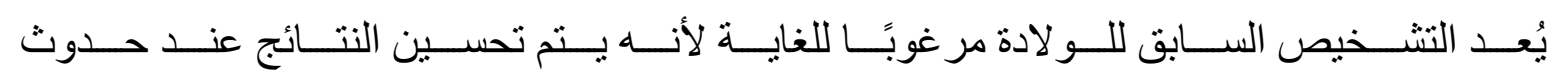

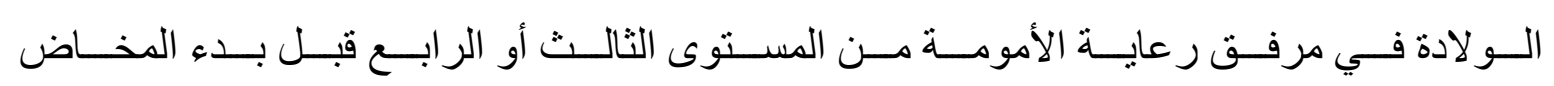

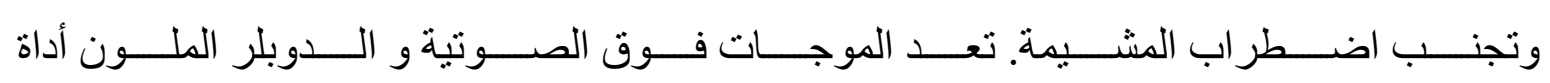

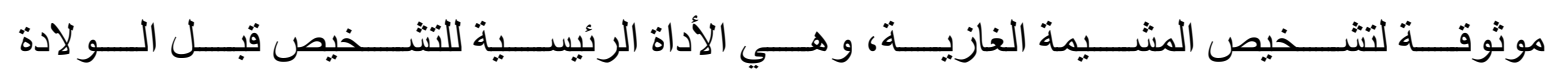

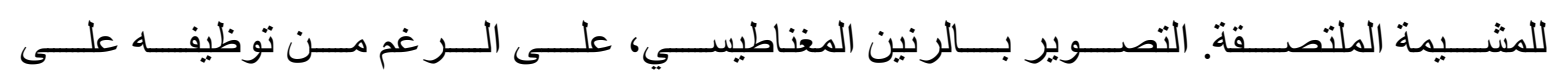
نطاق و اسع، لم يثبت بوضو ح تحسن كبير في نتائج الحمل.

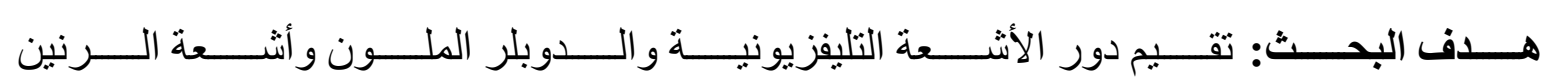
المغناطيسى فى تشخيص المشيمة الملتصقة.

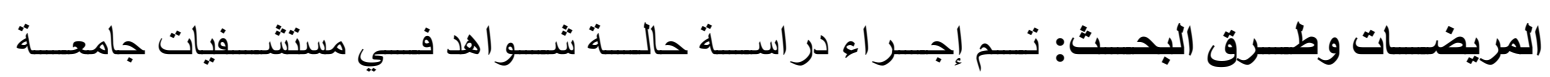

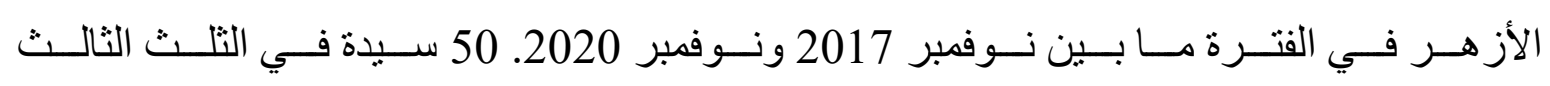

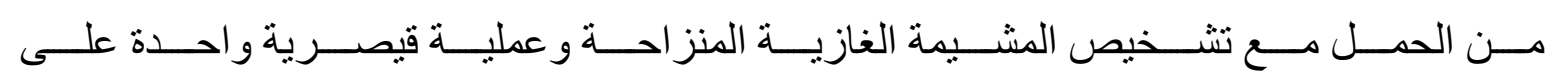

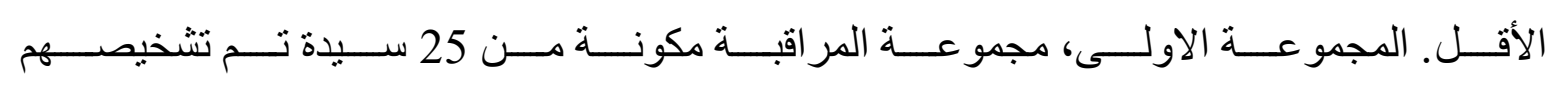

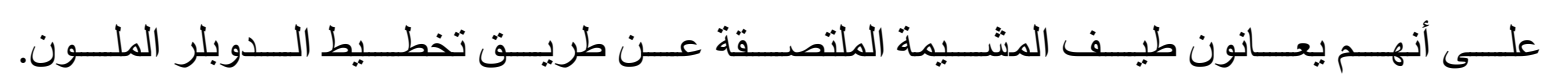

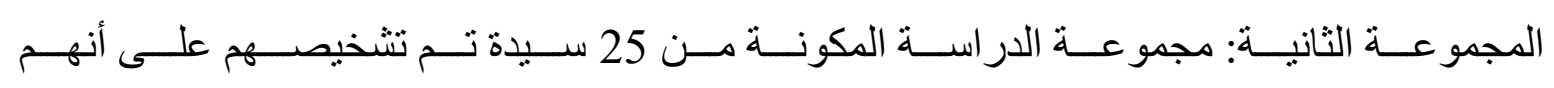

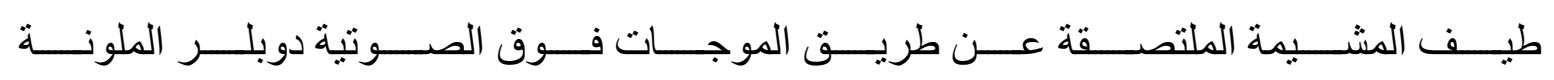




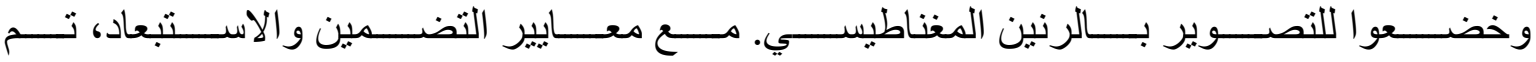

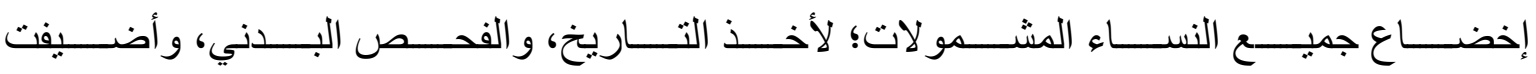

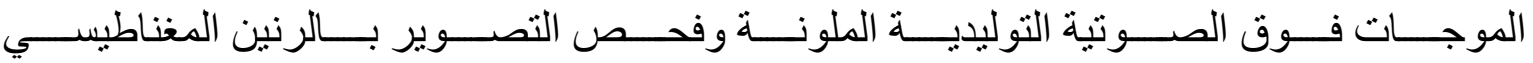
للمجمو عة الثانية فقط لالتقاط السمات التي توحي بطيف المشيمة الملتصقة.

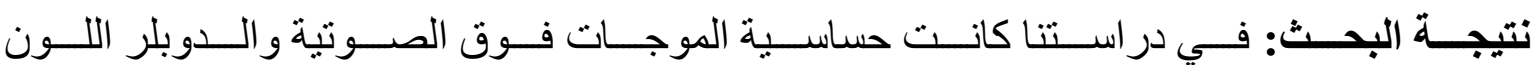

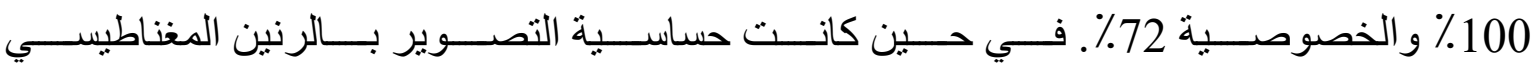

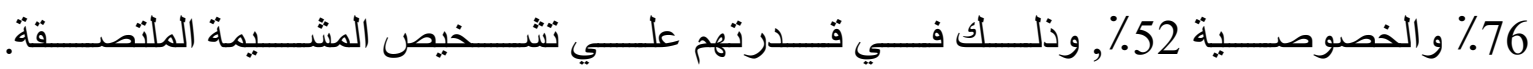

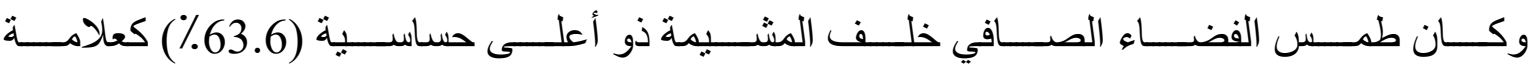

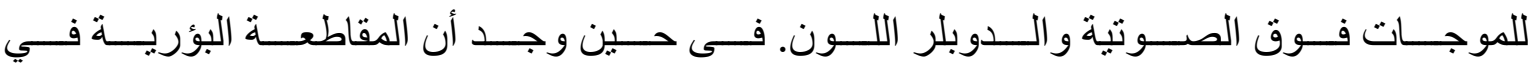

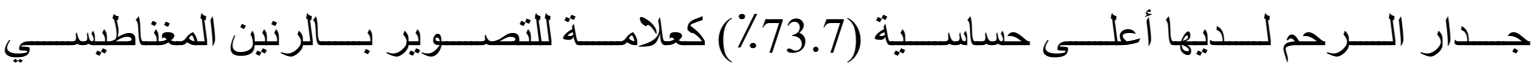
علي تتخيص المشيمة الملتصقة.

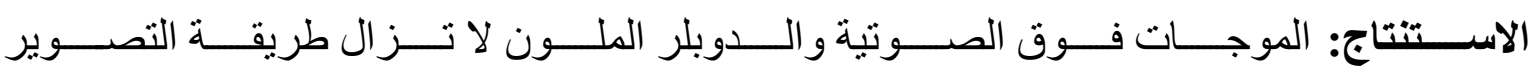

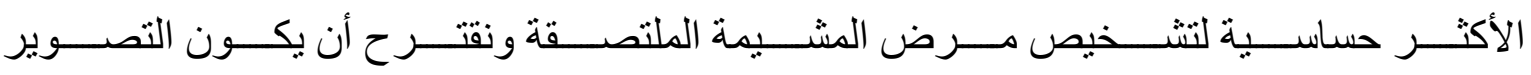

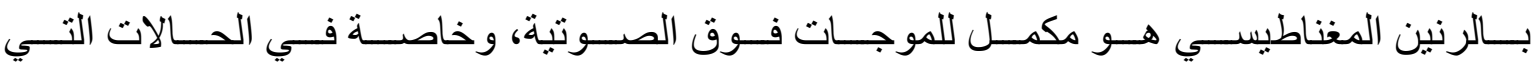

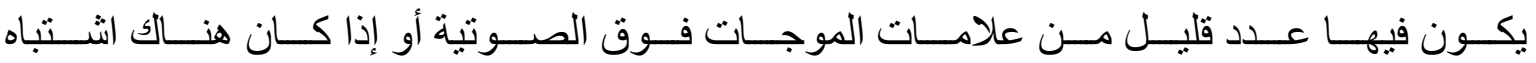
فى وجود غزو في الأنسجة المجاورة للرحم.

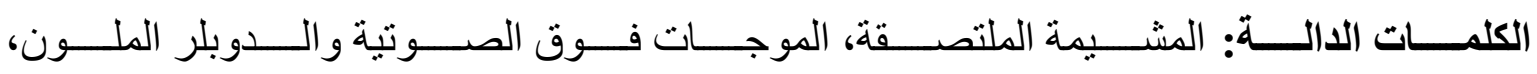

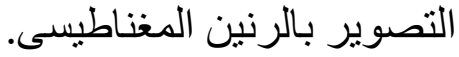

